Erratum

\title{
Erratum to "Coagulation and Sedimentation of Concentrated Laterite Suspensions: Comparison of Hydrolyzing Salts in Presence of Grewia spp. Biopolymer"
}

\author{
Kameni Ngounou M. Bernard (D), Ndi K. Sylvere, Kofa G. Patrice $\mathbb{D}^{D}$, and Kayem G. Joseph \\ Industrial Filtration and Water Treatment (Chem. Eng.) Group, Department of Process Engineering, ENSAI, \\ University of Ngaoundere, Cameroon \\ Correspondence should be addressed to Kameni Ngounou M. Bernard; kameningounoumichelbernard@gmail.com \\ Received 14 March 2019; Accepted 21 March 2019; Published 5 May 2019 \\ Copyright (c) 2019 Kameni Ngounou M. Bernard et al. This is an open access article distributed under the Creative Commons \\ Attribution License, which permits unrestricted use, distribution, and reproduction in any medium, provided the original work is \\ properly cited.
}

In the article titled "Coagulation and Sedimentation of Concentrated Laterite Suspensions: Comparison of Hydrolyzing Salts in Presence of Grewia spp. Biopolymer" [1], the city "Ngaoundere" should be removed from the authors' affiliation. The corrected affiliation is shown above.

\section{References}

[1] K. N. M. Bernard, N. K. Sylvere, K. G. Patrice, and K. G. Joseph, "Coagulation and sedimentation of concentrated laterite suspensions: comparison of hydrolyzing salts in presence of Grewia spp. biopolymer," Journal of Chemistry, vol. 2019, Article ID 1431694, 9 pages, 2019. 


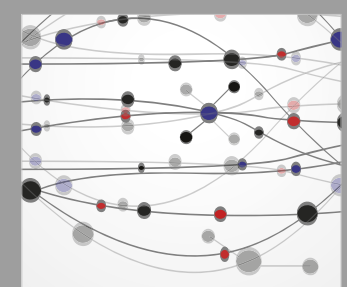

The Scientific World Journal
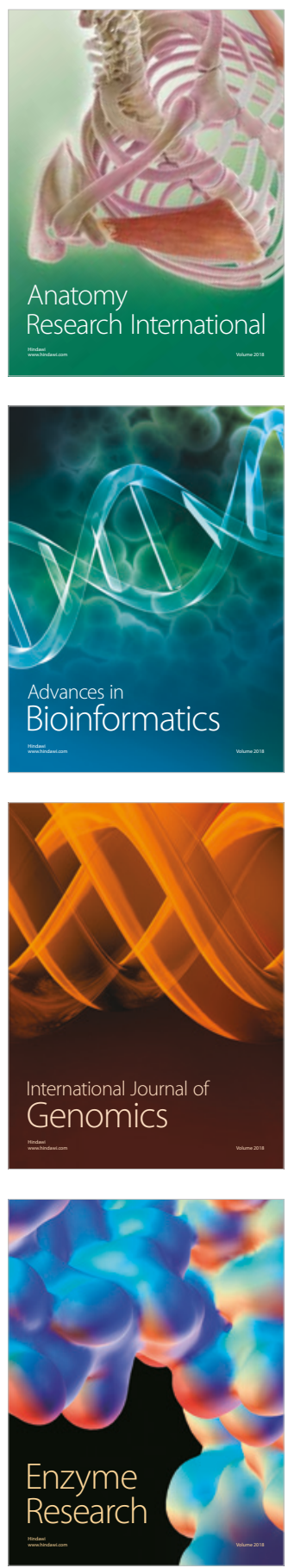
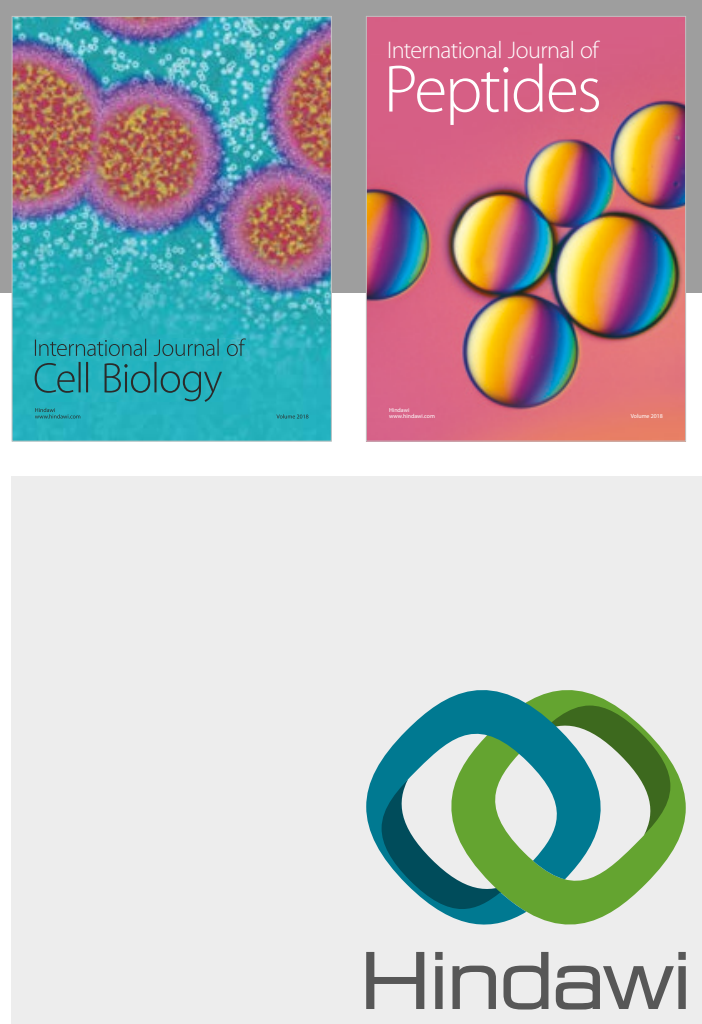

Submit your manuscripts at

www.hindawi.com
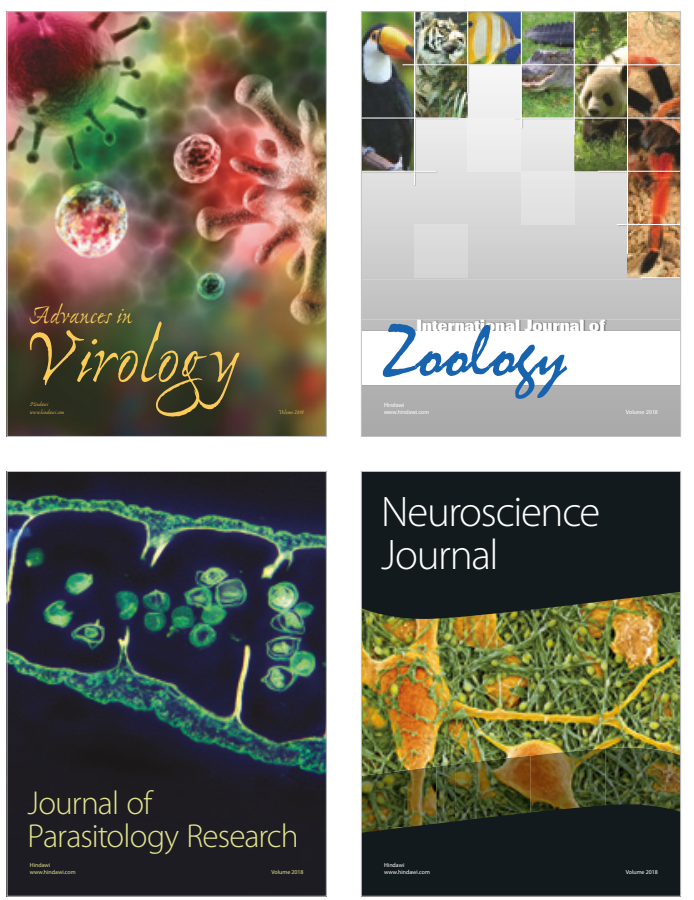
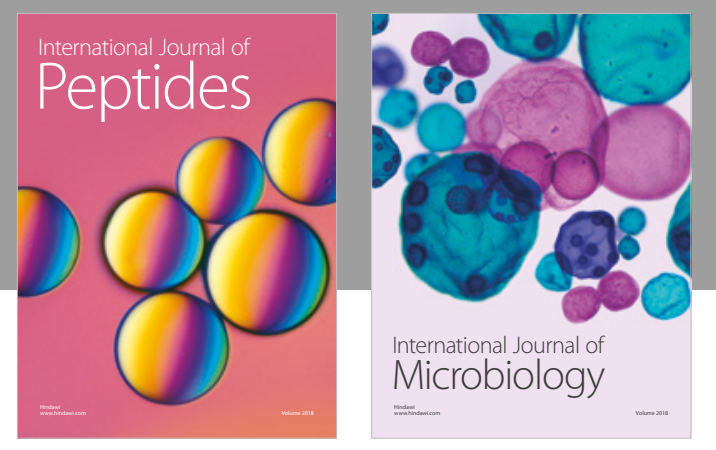

nternational Journal of Microbiology
Journal of
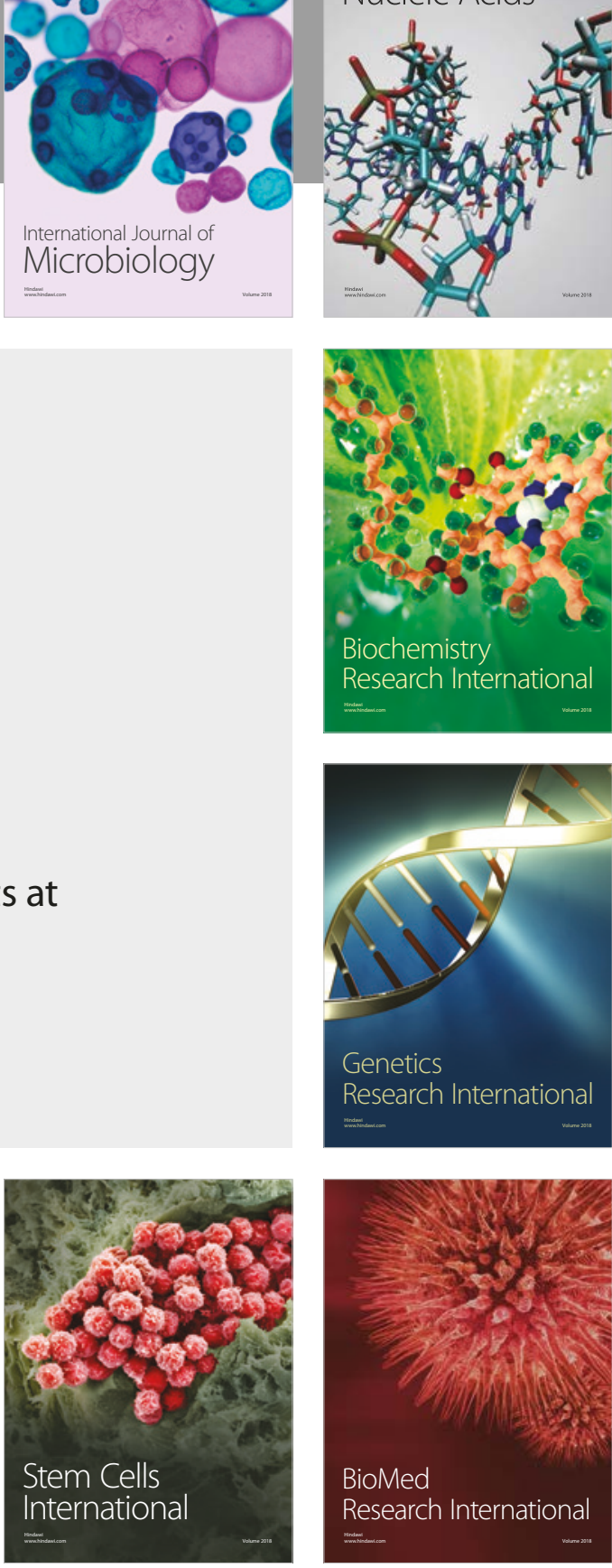
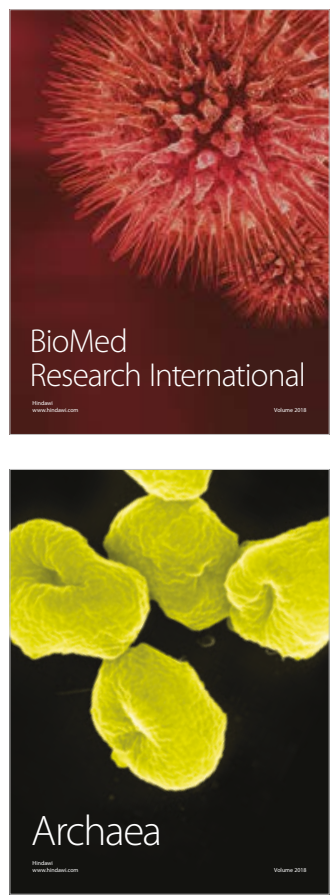